\title{
Ensino remoto de matrizes: o uso da WebQuest como recurso digital para propiciar a aprendizagem significativa
}

\author{
Paula Boito ${ }^{1}$ \\ UPF, Passo Fundo, RS \\ Rosana Maria Luvezute Kripka ${ }^{2}$ \\ UPF, Passo Fundo, RS \\ Eduarda Cericato Ferrareze ${ }^{3}$ \\ UPF, Passo Fundo, RS
}

\begin{abstract}
Resumo. O presente trabalho tem por objetivo apresentar uma experiência, vivenciada no período da pandemia da COVID-19, com a utilização de uma WebQuest, desenvolvida sobre matrizes e operações, como alternativa pedagógica para o ensino de matemática. A WebQuest foi elaborada por um grupo de pesquisa da Universidade de Passo Fundo (UPF) e utilizada por 108 estudantes do $2^{\circ}$ ano do Ensino Médio, de uma escola privada do Rio Grande do Sul. Devido à pandemia da COVID-19 e às características da proposta, percebeu-se que essa estratégia pedagógica também poderia ser usada no ensino remoto. Verificou-se que a metodologia possibilitou o estímulo da autonomia dos estudantes na aprendizagem, pois, durante o processo, eles puderam se aprofundar no tema sem a interferência do professor, o qual participou como mediador na construção desse conhecimento. Ao término da proposta, pelas avaliações realizadas pelo professor e pelos relatos dos estudantes, foi possível perceber que além de despertar o interesse dos estudantes, a WebQuest propiciou um ambiente de aprendizagem significativa dos conceitos abordados.
\end{abstract}

Palavras-chave. Ensino e aprendizagem, WebQuest, Tecnologias Digitais, Matrizes

\section{Introdução}

Atualmente, tanto a educação, quanto a comunicação, têm sido influenciadas diretamente pelas tecnologias digitais de informação e de comunicação (TDIC) e essa inserção na sociedade tem mudado os meios e modos de comunicação, oferecendo diversas possibilidades para diferentes usos ( [9]; [7] ).

Nos processos educativos essas mudanças também devem ser consideradas de modo a contemplar esses novos modos de aprendizagem ( [1])

Nesse sentido, o papel do professor deve ser de orientador e mediador de tarefas, estimulando a autonomia do estudante ( [8]). Também cabe ao professor o planejamento de ambientes favoráveis à aprendizagem, fazendo uso adequado das tecnologias digitais em situações de ensino.

Dentre as inúmeras tecnologias digitais, destaca-se o recurso tecnológico chamado WebQuest. Trata-se de uma alternativa pedagógica que permite explorar diversas estratégias de ensino e de aprendizagem na área da matemática, a qual possibilita ao estudante assumir um papel ativo na sua aprendizagem e ao professor o papel de mediador nesse processo ( [3]).

\footnotetext{
${ }^{1}$ paulaboito@upf.br

2 rkripka@upf.br

3 eduardacericato@hotmail.com
} 
A WebQuest foi desenvolvida por Dodge ( [2]) e se trata de uma investigação orientada, a qual foi proposta para ser aplicada em sala de aula presencial, com uso de computadores. É disponibilizada aos estudantes por meio de um site da World Wide $W e b(W W W)$, na qual algumas, ou todas, as informações com as quais os estudantes interatuam são originadas de recursos disponíveis na própria $W W W$, os quais são previamente selecionados pelo professor, como arquivos informativos, vídeos e sites. A estrutura da WebQuest é elaborada e organizada em seis partes: introdução, tarefa, processos, recursos, avaliação e conclusão.

O uso da WebQuest como uma estratégia metodológica para o ensino escolarizado estimula os estudantes a se iniciarem na experiência de aprendizagem por meio de processos investigativos na construção do saber, pois possibilita o acesso a um conjunto de informações relevantes sobre um determinado assunto, que pode ser explorado conforme as necessidades de cada estudante.

Fim e Kripka ( [4], p. 56) ao apresentarem resultados de uma pesquisa bibliográfica envolvendo trabalhos científicos que abordaram sobre a aprendizagem em matemática por meio de WebQuests, no contexto da sala de aula presencial, concluem que essa estratégia pedagógica pode ser interessante ao professor pois possibilita: "[...] criar ambientes de ensino que favorecem a aprendizagem construcionista e colaborativa, o que favorece a compreensão em matemática e dinamiza conteúdos curriculares no contexto da sala de aula."

Esses indicativos foram confirmados pelas autoras Kripka, Silva e Ferrareze ( [6], p. 286) ao apresentarem os resultados de uma experiência vivenciada no âmbito da sala de aula, com uso de uma WebQuest para o ensino e a aprendizagem de equações de $2^{\circ}$ grau. As autoras indicam que a proposta didática do uso da WebQuest em sala de aula presencial é uma alternativa interessante e viável, pois a abordagem:

[...] possibilitou aos estudantes: despertar os interesses por meio dos recursos disponibilizados; estimular a autonomia, a participação ativa e interativa na construção dos próprios conhecimentos, e, ao professor, possibilitou atuar como um mediador na construção do conhecimento.

Neste trabalho apresenta-se um relato de experiência, vivenciado a partir do uso de uma $W e b$ Quest desenvolvida para o ensino e para a aprendizagem do conceito de matrizes e operações entre matrizes. Apesar desta WebQuest ter sido inicialmente elaborada para utilização em sala de aula presencial, ela se mostrou uma alternativa interessante para uso no ensino remoto, conforme apresenta-se a seguir.

Por suas características, esse recurso tecnológico digital apresenta uma sequência didática para abordagem de um assunto escolhido e possui tarefas completas, com níveis de dificuldades crescentes, incluindo avaliações já disponíveis, dispensando a elaboração de materiais complementares, facilitando, assim, a proposta de ensino do professor. Além disso, estimula a autonomia do estudante, o qual pode respeitar o seu próprio ritmo e tempo de aprendizagem.

\section{Metodologia}

A WebQuest sobre matrizes utilizada foi elaborada por um grupo de pesquisa da Universidade de Passo Fundo, em 2019, constituído de uma professora pesquisadora e uma bolsista de iniciação científica. Ela está disponibilizada no link https://sites.google.com/view/webquestmatrizesupf. (ver Figura 1)

Devido a pandemia da COVID-19, a aplicação desta proposta, diferentemente do planejamento inicial (uso em sala de aula presencial), foi realizada de maneira remota, para estudantes de três turmas do $2^{\circ}$ ano do Ensino Médio, de uma escola privada do Rio Grande do Sul, totalizando 108 estudantes. 


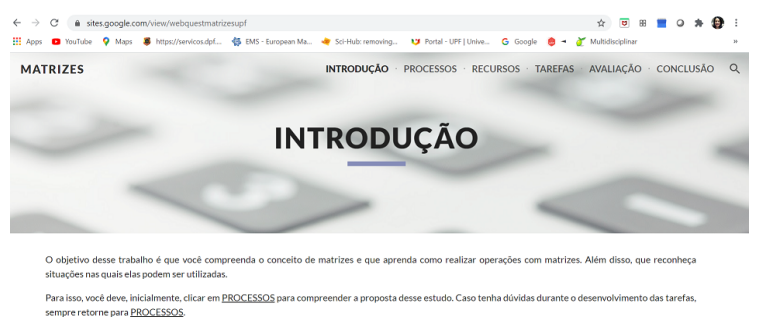

Figura 1: Imagem da página inicial da WebQuest sobre Matrizes está disponibilizada.

De acordo com as orientações pedagógicas dessa escola, o estudo de matrizes fazia parte do conteúdo previsto para ser abordado no primeiro trimestre.

Inicialmente, foi apresentada a estrutura da WebQuest, por meio de uma aula síncrona, realizada por meio do Google Meet, mostrando aos estudantes os recursos disponíveis, na qual também foram orientados sobre como poderiam explorar o site.

Como proposta inicial, o link da WebQuest foi enviado via Classroom aos estudantes, apenas com a seguinte orientação: "Explorar a WebQuest sobre matrizes e entregar a Tarefa 1", que já estava disponível.

$\mathrm{Na}$ aula seguinte, os estudantes socializaram suas vivências com a WebQuest relatando, verbalmente, que perceberam ser um "novo modo de aprendizagem", o qual envolvia tecnologias digitais já conhecidas, porém usadas com uma finalidade com a qual não estavam acostumados. Também afirmaram terem gostado da estrutura oferecida por meio desse recurso, pois perceberam que todas as informações relevantes já estavam reunidas, o que facilitou o acesso ao conteúdo disponibilizado e a aprendizagem dos conceitos propostos.

Ao final dessa aula também foi realizada a correção da tarefa, quando a professora interviu mediando o processo de aprendizagem.

Assim, a sequência das aulas ocorreu, conforme as orientações propostas no próprio site da WebQuest, e as tarefas foram consideradas no processo avaliativo.

Na proposta foram utilizadas diversas situações problema relacionadas à conhecimentos cotidianos de modo a aproximar os conceitos abstratos, de definição de matrizes e operações, de situações práticas.

Como exemplo, na Tarefa 2, para compreensão sobre possibilidades de usos de matrizes, foi sugerido que assistissem ao vídeo: "Cooperativa de leite" (https://m3.ime.unicamp.br/recursos/1076).

Em seguida, foram desafiados a pensarem na resolução do seguinte problema:

1) Cinco escolas pertencentes à rede de Passo Fundo desejam organizar um encontro para realizar um campeonato de jogos de vôlei. Uma das cinco escolas será o local desse encontro. Para definir qual escola será escolhida para sediar os jogos, será utilizado o critério da menor distância percorrida. A escola que sediará o campeonato deve ser escolhida de modo que a maior distância a ser percorrida pelos estudantes, professores e jogadores pertencentes às cinco escolas seja a menor possível. As escolas que farão parte deste campeonato são: Instituto Menino Deus, Escola Estadual de Educação Básica Nicolau de Araújo Vergueiro (EENAV), Ensino Médio Integrado UPF, INST Estadual Cardeal Arcoverde e Colégio Marista Conceição. Usando o Google Maps, elabore uma matriz para descobrir qual escola deve ser escolhida, de modo que a maior distância a ser percorrida pelos estudantes, professores e jogadores das escolas seja a menor possível.

Nesse caso, destaca-se que também foi estimulado o uso da Geotecnologia Google Maps para que estimassem as distâncias aproximadas entre as escolas, de modo a resolver o problema proposto. 
Outra situação problema foi proposta na Tarefa 3, a qual visava estimular a compreensão das operações entre matrizes, conforme apresenta-se a seguir:

3) Fazendo uso do conhecimento adquirido sobre matrizes e suas operações, resolva o seguinte problema: "Uma loja de materiais de construção entre alguns de seus produtos mais vendidos tinha um estoque, no início de mês: 600 sacos de cimento, $50 \mathrm{~m}^{3}$ de areia, 550 sacos de argamassa para porcelanato, 400 sacos de rejunte para porcelanato, 20 bacias para banheiro, 15 kits para instalação de bacias para banheiro, 20 cubas para banheiro, $500 \mathrm{~m}^{2}$ de piso porcelanato. Para evitar a falta destes produtos a pronta entrega, foram repostos, na metade do mês: 200 sacos de cimento, $15 \mathrm{~m}^{3}$ de areia, 250 sacos de argamassa para porcelanato, 150 sacos de rejunte para porcelanato, 8 bacias para banheiro, 8 kits para instalação de bacias para banheiro, 10 cubas para banheiro e $350 \mathrm{~m}^{2}$ de piso porcelanato. No entanto, ao longo do mês foram vendidos: 450 sacos de cimento, $35 \mathrm{~m}^{3}$ de areia, 420 sacos de argamassa para porcelanato, 340 sacos de rejunte para porcelanato, 12 bacias para banheiro, 10 kits para instalação de bacias para banheiro, 9 cubas para banheiro e $480 \mathrm{~m}^{2}$ de piso porcelanato. Calcule: a) Qual o estoque da loja no final do mês em relação aos produtos citados? b) Quanto deve ser comprado de cada item, no final do mês, para repor o estoque para o início do próximo mês? c) Considerando que os preços dos produtos dos produtos são: saco de cimento - R\$31,90; $\mathrm{m}^{3}$ de areia - RS125,00; saco de argamassa para porcelanato - $\mathrm{R} \$ 20,90$; saco de rejunte para porcelanato - $\mathrm{R} \$ 36.50$; bacia para banheiro - $\mathrm{R} \$ 469,00$; kit para instalação da bacia - $\mathrm{R} \$ 23,00$, cuba para o banheiro - $\mathrm{R} \$ 219,90 ; \mathrm{m}^{2}$ do porcelanato $\mathrm{R} \$ 49,90$, calcule os valores estimados dos estoques no início do mês, após a reposição e no final do mês. d) Supondo que a loja compre os itens a preço de custo, sendo em média a $38 \%$ mais baratos, calcule os valores de custo de cada item considerado. e) Caso uma empreiteira compre: 80 sacos de cimento, $8 \mathrm{~m}^{3}$ de areia, 150 sacos de argamassa para porcelanato, 70 sacos de rejunte para porcelanato, 4 bacias para banheiro, 4 kits para instalação de bacias para banheiro, 4 cubas para banheiro e $380 \mathrm{~m}^{2}$ de piso porcelanato e outra construtora compre: 38 sacos de cimento, $3 \mathrm{~m}^{3}$ de areia, 50 sacos de argamassa para porcelanato, 28 sacos de rejunte para porcelanato, 2 bacias para banheiro, 2 kits para instalação de bacias para banheiro, 2 cubas para banheiro e 80 $\mathrm{m}^{2}$ de piso porcelanato, calcule quanto cada uma pagará por suas compras.

$\mathrm{Na}$ avaliação final também foram propostas situações problemas que objetivavam sempre propiciar a interação de novas informações aos conceitos já existentes, tendo em vista propiciar a compreensão com significados, do conceito de matriz e das operações entre elas. Um deles inclusive foi elaborado considerando informações sobre o "Cartola FC", que é um jogo eletrônico de futebol estilo Fantasy Games, ou seja, é um jogo fictício no qual as pessoas montam seus times com jogadores inscritos oficialmente na Série A do Campeonato Brasileiro, o qual é muito famoso entre os estudantes.

As dúvidas, que eles não conseguiam esclarecer sozinhos, com uso dos materiais disponibilizados, foram sendo esclarecidas nas aulas síncronas, realizadas após as entregas das tarefas.

No total, foram utilizados seis períodos, dentre os quais três deles foram realizados de modo assíncrono, para que os estudantes explorassem os recursos oferecidos pela WebQuest, e os outros três foram realizados de maneira síncrona, para correção e discussão dos resultados das tarefas avaliativas. 


\section{Resultados e Discussões}

A WebQuest, ao ser apresentada às turmas, por conter todas as informações necessárias para a aprendizagem dos conceitos, motivou os estudantes no desenvolvimento das tarefas.

Percebeu-se, desde o início, que eles gostaram da proposta e um dos motivos foi pelo fato da abordagem ser diferente da habitualmente adotada pela professora. Também se percebeu que os estudantes se sentiram confiantes e empolgados com a metodologia, pois já estavam familiarizados com a dinâmica de pesquisa por meio de hipertextos e, também, pelo fato de terem acesso à vários recursos tecnológicos digitais previamente escolhidos e disponibilizados no site (videoaulas, slides ou textos), que facilitavam seus estudos.

Um exemplo de resolução que ilustra a compreensão do conceito de matrizes pode ser visualizado nas Figura 2 e Figura 3, quando os estudantes, para responderem as perguntas, construíram matrizes para armazenar os dados no problema proposto.

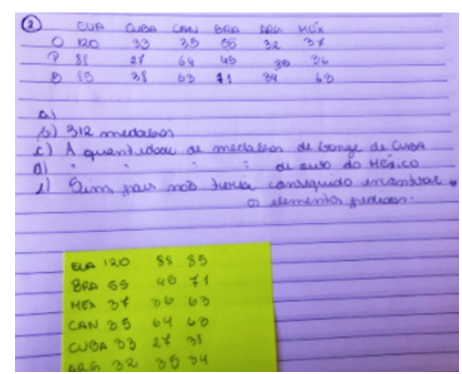

Figura 2: Registros da resolução do exercício 2 do estudante E1, da Tarefa 1.

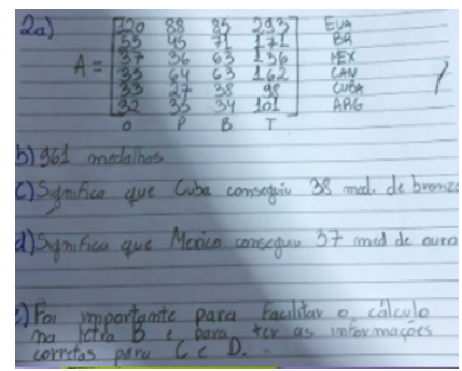

Figura 3: Registros da resolução do exercício 2 do estudante E2, da Tarefa 1.

Como no item (a) a escolha da disposição dos dados em linhas, ou colunas, era livre, nos exemplos apresentados, nas Figuras 2 e 3, se observa que o primeiro estudante (E1) optou por relacionar as linhas aos tipos de medalhas e as colunas aos países correspondentes, obtendo uma matriz de ordem 3x6. Também se observa na Figura 2 que o estudante não acrescentou uma linha contendo os totais de medalhas de cada país, conforme solicitado na questão. Já o segundo estudante (E2) armazenou os mesmos dados, porém, optou por armazenar os países em linhas e os tipos de medalhas em colunas, e ainda, acrescentou em sua representação tabular uma coluna a mais, na qual armazenou os totais de medalhas de cada país, obtendo uma matriz de ordem $6 \times 4$ (ver Figura 3)

Ainda se observa, na Figura 2, que o estudante E1 para responder o item (c), provavelmente ao tentar localizar o elemento $a_{53}$, percebeu a necessidade de construir a matriz transposta, que inclusive anexou com um post-it junto à resolução inicial. E ao fazer essa análise, isso o possibilitou 
responder aos outros itens de acordo com o que era esperado. Na resolução desse problema, ao final, também se fez a seguinte pergunta aos estudantes: "A elaboração da matriz foi importante nesse problema? Explique."

Todos afirmaram que sim e justificaram, demonstrando que compreenderam sua importância para organização e para localização de dados. Como exemplos, podem ser citados os seguintes fragmentos de registros escritos: "Sim, porque toda a informação fica concentrada/simplificada."; "Foi importante para facilitar o cálculo da letra (b) e para ter as informações corretas para (c) e (d).", e, ainda, "A construção da matriz facilita o entendimento com a localização dos números."

De acordo com as manifestações verbais iniciais dos estudantes, ocorridas durante aulas síncronas, foi possível perceber que a intencionalidade de facilitar o acesso às informações relevantes sobre o assunto, oferecendo uma seleção de materiais potencialmente significativos, estimulou a interação entre conceitos subsunçores e novas informações, o que propiciou um ambiente de aprendizagem significativa, conforme se pretendia.

Além disso, foi possível perceber que essa dinâmica dispensou o tempo gasto pelos estudantes com buscas aleatórias no vasto campo da $W W W$. Muitas vezes, essas buscas acabam gerando dificuldades, tendo em vista que ainda não estão preparados para a seleção de materiais bem elaborados, tanto do ponto de vista pedagógico, quanto do ponto de vista do próprio conteúdo, de modo que sejam confiáveis.

Conforme previsto no planejamento, como as tarefas envolviam níveis de dificuldade crescente, percebeu-se que, ao se depararem com questões que envolviam resolução de problemas mais complexos, eles apresentavam mais dificuldades de compreensão, o que é já era esperado. No entanto, com a mediação da professora, realizada em aulas síncronas, as dúvidas foram esclarecidas e as dificuldades superadas.

Ao final da proposta, pelo acompanhamento das evoluções dos estudantes (realizadas por meio da verificação dos registros escritos, em tarefas ou avaliações), percebeu-se que a maioria dos estudantes aprendeu os conceitos e que indicaram ter gostado da experiência, pois se sentiram sujeitos do processo de aprendizagem, participando ativamente na construção do conhecimento.

\section{Conclusões}

Os resultados dessa experiência indicam que além de propiciar a aprendizagem sobre matrizes e suas operações, a metodologia de ensino proposta por meio da WebQuest foi bem aceita pelos estudantes, os quais relataram, verbalmente, ter gostado da abordagem, inclusive sugerindo o uso posterior dessa proposta em outros temas.

Também se constatou, com essa experiência, que os estudantes tiveram a oportunidade de ampliar suas compressões sobre novas possibilidades de uso das tecnologias digitais para aprendizagem de conteúdos escolares. Ou seja, com uma finalidade bem diferente dos usos habituais (jogos, redes sociais, entretenimento, etc.). Assim, esse território já conhecido por eles, apresentou desafios, o que provavelmente estimulou a busca pelos novos conhecimentos propostos.

Nesse sentido, pode se constatar que essa experiência colaborou para ampliar as visões de mundo dos estudantes, pois, conforme indica Kenski ( [5], p.49):

Toda aprendizagem, em todos os tempos é mediada pelas tecnologias disponíveis. [...]

Essas aprendizagens não estão apenas direcionadas para o domínio de determinados conteúdos ou competências específicas. De uma forma ampla e complexa elas determinam os valores, as ações e a visão de mundo de cada pessoa e do grupo social no qual ela vive.

Além disso, segundo a percepção da professora, a qual fez uso desse recurso como estratégia alternativa inovadora em sua prática, os resultados obtidos superaram suas expectativas iniciais. 
Segundo ela, além de propiciar a aprendizagem sobre matrizes e suas operações, o que foi percebido durante o processo e em diversos momentos de avaliação propostos, a metodologia de ensino surpreendeu ao despertar o interesse dos estudantes, os quais solicitaram usos futuros de novas WebQuests para o estudo de outros assuntos da área de matemática.

Em relação aos objetivos iniciais da pesquisa realizada, destaca-se que foi possível verificar que a WebQuest se constitui como uma alternativa viável, que pode ser aplicada tanto no ensino presencial, conforme já destacado por Fim e Kripka ( [4]) e por Kripka, Silva e Ferrareze ( [6]), como no ensino remoto. Com a experiência relatada sobre o ensino remoto, percebeu-se que esse recurso tecnológico digital estimula a participação ativa dos estudantes na construção do próprio conhecimento, pois possibilita a interação autônoma com um ambiente que propicia a aprendizagem significativa de conceitos e, ainda, permite a intervenção do professor como um mediador, o qual atua como orientador em todo o processo de aprendizagem.

\section{Agradecimentos}

Agradecemos à Universidade de Passo Fundo pelo apoio à pesquisa desenvolvida.

\section{Referências}

[1] Borba, M. C. e Villarreal, M. E. Humans-with-media and the reorganization of mathematical thinking: information and communication technologies, modeling, experimentation and visualization. Springer, New York, 2005.

[2] Dodge, B. WebQuests: a technique for Internet-based learning. The Distance Educator.. v. 1, 2:10-13, 1995.

[3] Fim, C., F.; Pinto, P. C. e Kripka, R. M. L. Utilização da metodologia WebQuest nas aulas de matemática: uma proposta para o estudo de matrizes. Revista Brasileira de Ensino de Ciências e Matemática (RBECM). v. 1, 1:32-40, 2018.

[4] Fim, C. F. e Kripka, R. M. L. Aprendizagem em matemática por meio de recursos da WebQuest: diferentes usos e indicativos. In: SOUZA, S. A. (Org.) O ensino aprendizagem face às alternativas epistemológicas 3 [recurso eletrônico]. Atena, Ponta Grossa Atena, 2020. 56-66 (Coleção O Ensino Aprendizagem face às Alternativas Epistemológicas)

[5] Kenski, V. M. Aprendizagem mediada pela tecnologia. Revista Diálogo Educacional. v. 4, n:47-56, 2003.

[6] Kripka, R. M. L.; Silva, L. D.; Ferrareze, E. C.. EXPERIÊNCIA COM USO DE UMA WEBQUEST PARA O ENSINO E APRENDIZAGEM DE EQUAÇÕES DE $2^{\circ}$ GRAU. In: Navarro, E. R.; Sousa, M. C. (Orgs.). Educação Matemática em Pesquisa: Perspectivas e Tendências - Volume 2 Editora Científica, Belo Horizonte, 2021, p. 285-304.

[7] Lévy, P. As tecnologias da inteligência: o futuro do pensamento na era da informática, $2 a$. edição. Trad. Carlos Irineu da Costa.Editora 34, Rio de Janeiro, 2010.

[8] Moran, J. M Ensino e aprendizagem inovadores com apoio de tecnologias. In: Moran, J. M.; Masetto, M. T. e Behrens, M. A. (Orgs.) Novas tecnologias e mediação pedagógica, 21a edição. Papirus, Campinas, 2013. 11-72. (Coleção Papirus Educação).

[9] Valente, J. A. A Comunicação e a Educação baseada no uso das Tecnologias Digitais de Informação e Comunicação Revista UNIFESO - Humanas e Sociais, 1:141-166, 2014. 